\title{
PRESENTATION AND MANAGEMENT OF DEEP NECK SPACE ABSCESS
}

\author{
M. Panduranga Kamath ${ }^{1}$, Ashok B. Shetty ${ }^{2}$, Mahesh Chandra Hegde ${ }^{3}$, Suja Sreedharan ${ }^{4}$, Kiran \\ Bhojwani $^{5}$, Padmanabhan K. ${ }^{6}$, Saurabh Agarwal ${ }^{7}$, Manoj Mathew ${ }^{8}$, Rajeev Kumar M.'
}

ABSTRACT : Objective : To study the presentation, etiology, microbiology and morbidity of deep
neck space infections.
Study Design : Retrospective study
Methods : 29 patients admitted in Kasturba Medical College Hospital, Mangalore, India between
January 1997 and December 2002 with deep neck space infections were included in the study.
Results : The most common space involved was the parapharyngeal space.No specific etiology was
determined in $38 \%$; an odontogenic cause was discovered in $28 \%$ of the patients; tonsillar/pharyngeal
infections in $24 \%$ of patients and foreign body impaction in $7 \%$ of cases.
The main morbidity was due to mediastinitis (5 patients). 1 patient succumbed to the disease. Mixed
flora with aerobic and anaerobic infections was identified in most of the cases.

Key Words : Deep neck space infections; Parapharyngeal space; Retropharyngeal space; Mediastinitis.

\section{INTRODUCTION}

Deep neck space infections affect fascial compartments of the head and neck and their contents. Although the incidence of Deep Neck Space infections was much higher in the pre-antibiotic era, it still continues to be a health problem. in third world countries, where it causes significant morbidity and mortality. Compared with infections elsewhere in the body, deep neck infections pose complicated problems, due to the numerous portals of entry of infection and proximity to vital structures. The increasing prevalence of patients with immunodeficiency or prior antibiotic treatment, may result in unusual clinical presentations and pathogens, making the clinical diagnosis and treatment difficult.

\section{MATERIALS AND METHODS}

Patients treated for deep neck abscesses at Kasturba Medical College Hospital, Mangalore between January 1997 and December 2002 were reviewed. Only patients with proven abscesses were included. Patients with pure peritonsillar abscesses, superficial infections of external neck wounds (surgical or traumatic), and abscesses related to fractures were excluded. Twenty-nine patients met these criteria and form the basis of this study. A details physical examination was carried out to determine the extent and cause of the deep neck space infections.

$\mathrm{X}$-ray neck (soft tissue) lateral view was taken in all patients. In 5 patients with suspected dental infection, orthopantomogram was taken to localize the infection. CT scan was taken in 12 patients with suspected parapharyngeal space/retropharyngeal space involvement. All patients underwent neck exploration for drainage of the abscesses and pus was sent for microbiological examination.

\section{RESULTS}

The study group included 29 patients, 16 male and 13 female patients. The mode of presentation of the abscesses is summarized in Table I. Dysphagia or odynophagia was the most common symptom, present in 19 patients (66\%); pain in neck was complained by 17 patients (59\%); swelling in the neck 17 patients $(59 \%)$; fever was the complaint of 14 patients $(48 \%)$; 6 patients $(21 \%)$ complained of tooth ache; respiratory difficulties were noted by 5 patients $(17 \%)$; and 3 patients $(10 \%)$ had a recent dental extraction.

Physical examination results are summarized in Table II. Swelling of the neck was the most common physical finding, present in 23 patients $(79 \%)$. Oropharyngeal abnormalities in the form of faucial bulge, swelling of the posterior pharyngeal wall were noted in 18 patients $(62 \%)$. Six patients $(21 \%)$ had dental abnormalities. Four of these patients had carious lesions of varying degree. Two of the patients had periodontal disease with marked

'Professor and Head of Department of ENT, ${ }^{2}$ Professor of Dept. of Cardiothoracic Surgery, ${ }^{3 .+5}$ Associate Professor. Department of ENT, ${ }^{6.7 .8 .9}$ Resident, Department of ENT, Kasturba Medical College Hospita1, Attavar, Mangalore - 575001, Karnataka, India. 
Table - I : Symptoms of Deep Neck Abscesses

\begin{tabular}{|l|c|c|}
\hline Symptom & $\begin{array}{l}\text { No. of } \\
\text { Patients }\end{array}$ & Percent \\
\hline Dysphagia/odynophagia & $19 / 29$ & $66 \%$ \\
Pain neck & $17 / 29$ & $59 \%$ \\
Swelling in neck & $17 / 29$ & $59 \%$ \\
Fever & $14 / 29$ & $48 \%$ \\
Toothache & $06 / 29$ & $21 \%$ \\
Respiratory difficulty & $05 / 29$ & $17 \%$ \\
Recent tooth extraction & $03 / 29$ & $10 \%$ \\
\hline
\end{tabular}

Table II : Physical Examination

\begin{tabular}{|l|l|l|}
\hline Finding & $\begin{array}{l}\text { No. of } \\
\text { Patients }\end{array}$ & Percent \\
\hline Swelling in neck & $23 / 29$ & $79 \%$ \\
Oropharyngeal abnormalities & $18 / 29$ & $62 \%$ \\
Trismus & $06 / 29$ & $21 \%$ \\
Dental abnormaity & $06 / 29$ & $21 \%$ \\
\hline
\end{tabular}

Table III : Etiology of neck abscesses

\begin{tabular}{|l|l|l|}
\hline Etiology & $\begin{array}{l}\text { No. of } \\
\text { Patients }\end{array}$ & Percent \\
\hline Unknown & $11 / 29$ & $38 \%$ \\
Odontogenic & $08 / 29$ & $28 \%$ \\
Tonsil/pharynx infection & $07 / 29$ & $24 \%$ \\
Recent trauma to area (Fish bone) & $02 / 29$ & $07 \%$ \\
Oesophageal malignancy & $01 / 29$ & $03 \%$ \\
\hline
\end{tabular}

tenderness. Marked halitosis was noted in 6 of the patients $(21 \%)$. Trismus was found in 6 patients $(21 \%)$.

Etiology of neck abscesses in this series is summarized in Table III. Etiology was unknown in majority of the patients. 8 patients $(28 \%)$ had odontogenic neck abscesses; 7 patients $(24 \%)$ had recent infection of tonsil or pharynx; 2 patients had recent trauma to the area of abscess (due to foreign body) and one was secondary to oesophageal malignancy.

Out of the 29 patients, 13 underwent temporary tracheostomy. Of these, 3 patients developed airway obstruction of sufficient degree to warrant emergency tracheostomy. The remaining 10 were elective tracheostomies.

All patients underwent incision and drainage of their neck
Table - IV : Location of abscesses

\begin{tabular}{|l|l|l|}
\hline Location & $\begin{array}{l}\text { No. of } \\
\text { Patients }\end{array}$ & Percent \\
\hline Parapharyngeal space & $14 / 29$ & $48 \%$ \\
Submandibular space & $09 / 29$ & $31 \%$ \\
Retropharyngeal space & $07 / 29$ & $24 \%$ \\
Mediastinum & $05 / 29$ & $17 \%$ \\
Anterior visceral space & $01 / 29$ & $03 \%$ \\
\hline
\end{tabular}

Table - V : Bacteria isolated from neck abscesses

\begin{tabular}{|l|l|l|l|}
\hline Anaerobes & & Aerobes & \\
\hline Peptostreptococcus & $15 / 29$ & $\begin{array}{l}\text { Streptococcus } \\
\text { pyogenes }\end{array}$ & $11 / 29$ \\
Bacteroides & $11 / 29$ & $\begin{array}{l}\text { Klebsiella } \\
\text { Staphylococcus } \\
\text { aureus } \\
\text { Streptococcus } \\
\text { pneumoniae } \\
\text { Fusobacteria } \\
\text { Haemophilus } \\
\text { influenza }\end{array}$ & $02 / 29$ \\
$01 / 29$ \\
$01 / 29$ \\
0
\end{tabular}

Fig. I : CT scan axial section $\left(\mathrm{C}_{4}\right.$ level) showing evidence of a parapharyngeal abscess in the left side.

abscesses and were administered intravenous antibiotics. 22 patients received combination regime of Crystalline Penicillin, Gentamicin and Metronidazole. 7 patients received combination of Cefotaxime and Metronidazole.

The location of abscesses was determined from operative notes. The distribution of abscesses among various areas is summarized in Table IV. Parapharyngeal space was the 


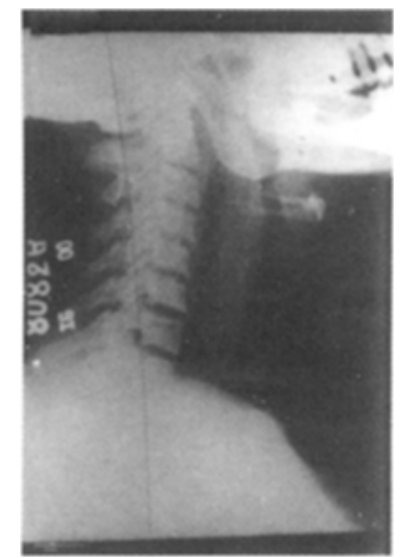

Fig. II : X-ray soft tissue neck, lateral view - increased prevertebral soft tissue thickness with mottled lucent areas extending from $\mathrm{C}_{2}-\mathrm{C}_{7}$ (retropharyngeal abscess).

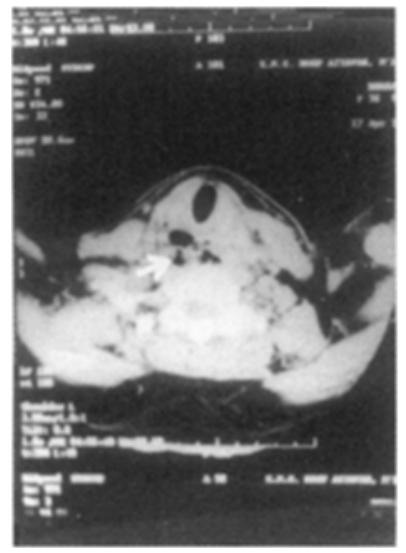

Fig. III : CT scan axial section ( $\mathrm{T}_{1}$ level) showing retro tracheal soft tissue enlargement extending to superior mediastinal and prevertebral spaces with air densities.

most common location, occurring in 14 patients (48\%). The next most common space involved was the submandibular space (31\%) and the retropharyngeal space in $(24 \%) .5$ patients $(17 \%)$ had mediastinal involvement; 5 patients had multiple neck space infections.

Five patients developed complication of neck abscesses. Case 1: A 23 year old female patient developed a parapharyngeal abscess of dental origin (Fig.I), complicated by septicemia, mediastinitis and empyema of both pleural spaces. In addition to drainage of neck abscesses the patient required bilateral thoracotomy and drainage, along with mechanical ventilation for two weeks. She was weaned off the ventilator. 4 weeks later, she developed severe pulmonary sepsis following aspiration and succumbed to it.

Case 2 : An adult male patient had chicken bone impaction in the cervical esophagus (Fig. II) with delayed

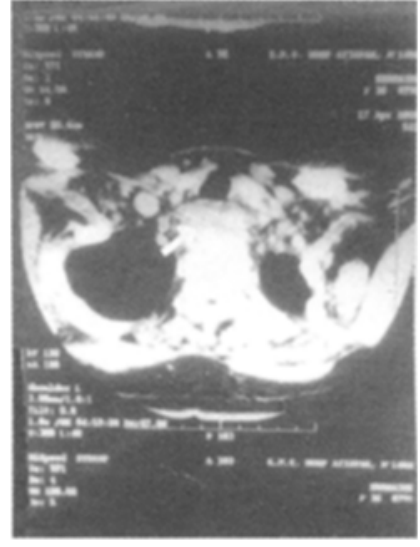

Fig. IV : CT scan axial section ( $\mathrm{T}_{2}$ level) of the same patient showing retrotracheal soft tissue enlargement extending to superior mediastinum and the pleural spaces.

presentation. He had a retropharyngeal abscess and mediastinitis with right sided loculated empyema due to perforation of the esophagus. The impacted bone was removed via esophagoscopy, followed by a cervical mediastinotomy and drainage. Subsequently, a fistulous connection was found between the esophagus and the right pleural cavity, which was successfully managed conservatively.

Case 3 : A 36 year old female patient presented with an impacted 'fish-bone' in the cervical esophagus. The case was complicated by the presence of both mediastinitis and empyema (Fig. III, IV). This was managed by esophagoscopy and removal of the 'fish bone', incision and drainage of the neck abscess, intercostal drainage and antibiotic therapy for 6 weeks.

Case 4 : An 8 year old boy had an anterior visceral space infection which extended to the mediastinum. He required a median sternotomy with extension of incision to the neck.

Case 5: A 57 year old male patient, had a parapharyngeal abscess secondary to a tumour in the upper $1 / 3^{\text {rd }}$ of esophagus, for which we did transcervical drainage of abscess with tracheotomy. Later, the patient was sent for radiotherapy. Feeding gastrostomy was done as the patient developed a pharyngocutaneous fistula; this subsequently healed.

Culture of neck abscesses were obtained in all the patients. Of the 29 patients 26 had positive cultures; 6 were pure cultures but 20 revealed multiple organisms. Table V 
demonstrates various types of bacteria isolated from the neck abscesses of which anaerobes predominated. Of the anaerobic species Peptostreptococcus and Bacteroides were the most commonly found with 15 and 11 isolated respectively. Of the aerobic species Streptococcus pyogenes and Klebsiella were the most common, with 11 and 8 isolates each. Staphylococcus aureus was isolated in 2 cases and Streptococcus pneumoniae, Hemophilus influenza, Fusobacteria were isolated in one case each.

All patients were hospitalized immediately and remained so for a mean of 18 days.

\section{DISCUSSION}

Etiology of deep neck infections varies depending on the space involved. In the pre antibiotic era, $70 \%$ of deep neck infections resulted from spread from pharyngeal and tonsillar infections ${ }^{1}$. In the post-antibiotic era, an increasing percentage of infections are odontogenic in origin which often involve the submandibular space and parapharyngeal space $^{2}$. Other causes include salivary gland infections, upper respiratory tract infections, trauma and foreign bodies'. Other rare causes are branchiogenic cysts ${ }^{3}$ instrumentation and spread of superficial infections. In addition to classic origins, deep neck space infections are also seen in intravenous drug abusers ${ }^{4}$ and hypopharyngeal malignancies ${ }^{5}$. No specific cause may be found in few cases; this may be as high as $50 \%$ as reported by Wright et $\mathrm{al}^{2}$.

Trauma of the upper aerodigestive tract by blunt, penetrating or iatrogenic cause is not an uncommon cause of deep neck space infection. A foreign body impacted in the esophagus should be removed as soon as the diagnosis is made for the following reasons : - the chance of spontaneous passage is small; edema from local trauma grips the object firmly, making later manipulation difficult, and perforation of the esophagus is a very serious complication, with high mortality and morbidity ${ }^{7}$.

Peritonsillar abscess or cellulitis (usually of streptococcal origin) may penetrate the buccopharyngeal fascia directly or extend by retrograde thrombophlebitis to involve the parapharyngeal space. The carotid sheath, which traverses the parapharyngeal space can get involved and provide a pathway of spread to mediastinum. Mosher named this potential avenue of infection the "Lincoln's Highway" of the neck'.
In pediatric population, acute tonsillitis with involvement of the peritonsillar space is the most common cause of deep neck infections. The second most common source is dental, with involvement of the submandibular space ${ }^{1}$. Retropharyngeal lymph nodes which are found in greater number in children and may become abscessed secondary to a primary focus in the nose, paranasal sinuses, pharynx, middle ear and eustachian tube, leading to a prevertebral space infection.

Other sources of neck infection are sialadenitis, Bezold's abscess, infection of congenital cysts and fistulas and extension of suppuration in deep cervical lymphatics ${ }^{2}$.

An untreated deep neck space infection spreads within a few days to the surrounding neck spaces. A submandibular neck infection spreads with relative ease to the parapharyngeal space; whence it may spread to the retropharyngeal space. A peritonsillar space infection can also take the same route to the retropharyngeal space. A parapharyngeal abscess can track down into the mediastinum via the "Lincoln's highway", but mediastinal involvement is commoner in a retropharyngeal abscess with its direct access to the superior mediastinum ${ }^{1}$.

These infections are usually of mixed microbiologic flora including alpha and beta Streptococci, Staphylococcus, Peptostreptococcus, Fusobacterium nucleatum, Bacteroides melanogenicus, Bacteroides oralis, Violonella, Actinomyces, Spirochaetes, Micrococcus and Eikenella corrodens $1,8 \& 14$. Rare cases due to Enterobacter, Enterococcus, Proteus, Propionobacter, Pseudomonas and Candida have also been reported ${ }^{8}$.

Deep neck space infections call for early diagnosis and prompt management. What Mosher said about deep neck infections in 1929 still holds true, "Pus in the neck calls for the surgeon's best judgement, his best skill and often for all his courage".

The best modality of investigation is the CT scan. Chest $\mathrm{X}$ - ray is mandatory if mediastinal involvement is suspected.

Securing and maintaining an adequate airway must be the first priority. Endotracheal intubation or tracheostomy is done as per the requirement of the case. Elective tracheotomy was done in most of our patients, as to secure 
the airway. The hydration is corrected, as these patients with neck space infections come with odynophagia, dysphagia and dehydration.

Aggressive intravenous antibiotic administration is a corner stone of therapy. The initial antibiotic cover is empiric, primarily targeted at gram positive cocci, with Pencillin being the drug of choice. Anaerobic cover with metronidazole should also be provided ${ }^{11}$.

Surgical drainage is indicated as an early procedure in the presence of any suppurative infection of the neck. Various skin incisions have been described for the different abscesses $^{2}$. The incision should give a wide access to the abscess with good control of adjacent neurovascular structures. Blunt dissection should be done in draining the abscess with great care to avoid injury to pharyngeal wall and neurovascular structures. Less commonly accepted management of deep neck space infections include CT guided aspiration ${ }^{(12)}$ and ultrasound guided needle aspiration ${ }^{10}$.

In children intraoral drainage is preferred, as the commonest site of infection is the retropharyngeal space or lateral pharyngeal space medial to the great vessels. External drainage is better reserved for abscesses which involve multiple spaces and which are lateral to the great vessels ${ }^{9}$.

Morbidity in the deep neck space infections is mainly due to mediastinal complications. In our study $17 \%$ patients developed mediastinitis and one patient succumbed to it. Mediastinal involvement calls for prompt management with high dose intravenous antibiotics, thoracotomy and drainage. The other main complications which are rarely seen are jugular vein thrombosis, carotid artery rupture and meningitis ${ }^{8}$.

Mediastinitis is one of the main causes of mortality in deep neck space infections. In our series we lost one patient to this dreaded complication giving a mortality rate of $3 \%$. This is comparable to the mortality figures quoted in literature ${ }^{14}$. Sethi et al has quoted a mortality rate of $8 \%$, with patients dying of necrotizing fascitis, multiorgan failure and cardiogenic shock. In lieu of the life threatening nature of the above mentioned complications, an early diagnosis and prompt surgical intervention of deep neck space infections is indicated.

\section{CONCLUSION}

Guidelines for the management of Deep Neck Space infections ${ }^{1}$ :

1. Immediate Hospitalization

2. Intravenous antibiotics preferably - Penicillin, Gentamicin and Metronidazole

3. Management of airway

4. Diagnostic radiographic procedure $-\mathrm{CT}$ scan

5. Incision and drainage.

\section{ACKNOWLEDGEMENT}

Authors are thankful to the Dean and Medical Superintendent, Kasturba Medical College and Dr. Ramdas Pai, Medical Director, Manipal Academy of Higher Education, for the permission to use the hospital records.

\section{REFERENCES}

1. Bruce A.Scott. Charles M. Stienberg and Brian P. Driscoll (1998): Deep Neck space Infections. In: Byron J. Bailey Head and Neck Surgery - Otolaryngology, second editon Lippincott-Raven publisher, (editors-Byron J. Bailey, Harold C. Pillsbury, Brain P. Driscoll) $819-35$.

2. Kevin A. Shumrick, Stanely A. Sheft, (1991) : Deep Neck Infections. Paparella Otolaryngology, vol. 1II, Third edition. W. B. Saunders Company ( editor-Richard Zoreb), 2545-63.

3. Virolainen E, Happaneimi J, Aitasalo K, Sounpaa J. (1979) : Deep Neck infections. Int. J. Oral Surg. 8 (6) : 407-11.

4. Schondorf J, Jungehulsing M, Brochhagen HG Pluisch F, Schultes A, Eckel H.(2000): Infections of the deep soft tissues of the neck in intravenous drug abuse. Laryngorhinootologie, 79 (3) : $171-3$ (Abstract).

5. Wong YK. Novotny GM. (1978) : Retropharyngeal space - a review of anatomy pathology and clinical presentation. J. Otolaryngol. $7(6): 528-36$.

6. Kamath MP, Shanmugam, Shetty AB, Prasad KC. (1998) : A rare complication of an impacted foreign body in the cricopharynx. Am. J. Otolaryngol. 19 (1): $61-65$.

7. Nandi P, Ong GB. (1978) : Foreign body in the esophagus : Review of 2394 case. Br. J. Surg. 65 (1) : 5-9.

8. Gidley PW, Ghorayeb BY, Steinberg CM. (1997) : Contemporary management of deep neck space infections. Otolaryngol Head Neck Surg $116(1): 16-22$.

9. Choi SS, Vezina LG, Grundfast KM. (1997) : Relative incidence and alternative approaches for surgical drainage of different types of deep neck space infections in children. Arch Otolaryngol Head Neck Surg ; 123 (12) : 1271-5.

10. Ochi K, Ogino S, Fukamizu K, Yazaki H, Ohashi T, Ashida H, Takeyama I. (1996) : US - guided drainage of deep neck space abscesses. Acta Otolaryngol Suppl ; $522: 120-3$. (Abstract).

11. Barakate MS, Jensen MJ, Hemli JM, Graham AR. (2001) : Ludwig's Angina : report of a case and review of management issues. Ann Otol Rhinol Laryngol. $110(5 \mathrm{Pt1}): 453-6$. 
12. De Marie S, Tjon A Tham RT, van der Mey AG, Meerdink G van Furth R, van der Meer JW. (1989) : Clinical infections and nonsurgical treatment of parapharyngeal space infections complicating throat infections. Rev Infect Dis. 11 (6) : $975-82$

13. Tom MB, Rice DH.(1998) : Presentation and Management of neck abscess : a retrospective analysis. Laryngoscope. 98 (8 Pt 1$) 877$ - 80 .

14. Sethi DS, Stanley RE. (1994) : Deep neck abscesses - changing trends. J. Laryngol Otol. $108(2): 138-43$.

\section{Address for Correspondence :}

Dr. M. Panduranga Kamath

Professor and Head of the Department of ENT

Kasturba Medical College Hospital,

Attavar, Mangalore, Karnataka

India. PIN - 575001

\title{
CYTODIAGNOSIS OF SUBMANDIBULAR SIALADENITIS WITH CRYSTALLOIDS MIMICKING METASTASIS
}

\author{
Chandrakala S.R.', Julian A. Crasta ${ }^{2}$, Shameem Shariff ${ }^{3}$
}

\begin{abstract}
Sialomegaly of submandibular gland, whether inflammatory or neoplastic can be clinically mistaken for lymphoid metastasis especially when encountered in an elderly patient. Other than the neoplastic lesions and usual inflammatory lesions rarely amylase crystalloids can evoke a granulomatous response and can result in sialomegaly. We report an interesting case which presented as a submandibular swelling and was clinically diagnosed as metastasis where the diagnosis of granulomatous response to crystalloids was made at FNAC. The aim of this report is to bring an awareness of the existence of such lesions and to highlight the role of FNAC in diagnosis of such lesions in order to avoid unnecessary surgeries.
\end{abstract}

Key Words: Amylase crystalloids, sialadenitis, FNAC

\section{INTRODUCTION}

Mass in the submandibular region would be due to enlargement of salivary glands or of regional lymph nodes. Both of these could be either inflammatory or neoplastic in nature. Metastatic process is the commonest cause of the cervical lymph node enlargement especially in elderly patients. Certain physiological substances can crystallize in the salivary glands causing sialadenitis which clinically mimics a metastatic process.

Fine needle aspiration cytology (FNAC) plays a vital role in the evaluation of mass in the cervical region and accurately distinguishes between salivary gland lesions and lymph node metastasis. It is a well established technique in the management of salivary gland disease where it helps in distinguishing inflammatory from neoplastic lesions and avoids unnecessary surgeries in about one third to one half of the cases.

We report an interesting case of an elderly male patient who presented with a submandibular swelling which was clinically suspected to be metastasis, but on FNA was diagnosed to have sialadenitis with amylase crystalloids.

\section{CASE REPORT}

A 60-year-old male presented to the surgical out patient department of St Johns' Medical College Hospital with

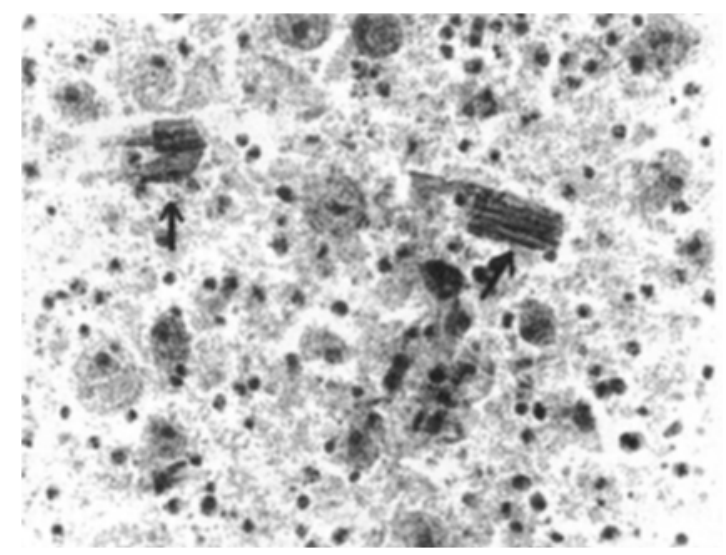

Fig.I : Rectangular crystals in the background of necrosis with macrophages. $(10 \mathrm{x})$

\footnotetext{
${ }^{1,2}$ Assistant Professor, ${ }^{3}$ Professor and Head, Department of Pathology, St. John's Medical College, Bangalore-560034, Karnataka, India
} 